\title{
A Study on WeChat-Based Collaborative Learning in College English Writing
}

\author{
Liping Yan ${ }^{1}$ \\ ${ }^{1}$ School of Foreign Languages, Leshan Normal University, Leshan, China \\ Correspondence: Liping Yan, School of Foreign Languages, Leshan Normal University, 778\#, Binhe Road, \\ Shizhong District, Leshan, Sichuan Province, China.
}

Received: March 25, 2019 Accepted: May 1, 2019 Online Published: May 2, 2019

doi: 10.5539/elt.v12n6p1 URL: https://doi.org/10.5539/elt.v12n6p1

\begin{abstract}
With the rapid development of mobile information technology and social media networks, it is feasible for college English teachers to get access to social networks such as QQ, Email and MSN as a way of practicing English writing beyond classroom. Similarly, it is also possible for teachers to utilize WeChat Platform where online communities for students and teachers can be established to combine collaborative and mobile learning together as a complementary way of classroom writing teaching. WeChat Platform, as the most popular software in China, owns the advantages of transmitting instant message, videos and pictures, which supplies students more chances to collaborate and interact with each other/one another at different stages of writing tasks. This research explores the application collaborative learning of college English writing on WeChat Platform. Based on the one-semester research as well as the questionnaire of the pre-test and post-test, it is revealed that, although there are still a few challenges for students and teachers to face, this mode of college English writing contributes to cultivating the students' team spirit, enhancing their initiative, improving their writing efficiency and developing their critical thinking by engaging in student-student and student-teacher collaboration and interaction, information sharing, communicating and socializing with classmates.
\end{abstract}

Keywords: WeChat, college English Writing, collaborative learning

\section{Introduction}

According to College English Teaching Guide promulgated by the Ministry of Education of China in 2017, English, as the most popular language in the world, is an important tool in the intercommunication of science, technology, economy and culture etc. On the foundation of English teaching in senior high school, the purpose of college English teaching is to promote the students' abilities of listening, speaking, reading, writing and translating. (Ministry of Education of China, 2017) Definitely, English writing capacity, in the five basic language skills, is the main part in the ability of language application for college students. However, college English writing has always been the weak point although both great efforts have been made in writing teaching and writing practice. Firstly, examination-oriented education forces college English teachers to focus on introducing the writing theories, expanding vocabularies and consolidating sentence structures. Secondly, teaching college English writing in big classroom, as the most traditional mode in China, due to limited teaching facilities and tight teaching plan, makes it not a student-centered class at all, but a teacher-centered class, which, to a large extent, limits the students' participation in class. The above two aspects result in students' lack of practice, collaboration, interaction, motivation, confidence and initiative. College English Teaching Guide elaborates clearly that the important task of foreign language teaching is to train and cultivate students' foreign language ability and that the teaching methods and modes directly affect the teaching effect and quality. (Ministry of Education of China, 2017) Teachers should make full use of the network teaching platform to provide learners with the independent learning path combined with modern information technology and rich independent learning resources, so as to promote students to change from "passive learning" to "active learning". (Ministry of Education of China, 2017)

With the rapid development of science, technology, information and communication, computers, laptops, IPads and smart phones have been popularizing among the people and the internet has entered the daily life of the public. In February, 2019, China Internet Network Information Center (CN-NIC) released $43^{\text {rd }}$ China Internet Development Report: Till December, 2018, the number of netizens has increased to 0.829 billion, in which there 
are 0.817 billion of mobile netizens. People who make use of WeChat as a form of social contact and instant messaging take a huge proportion of mobile netizens (83.4\%) (China Internet Network Information Center, 2019). Through the questionnaire, all young college students today are utilizing smart phones to surf the internet, to chat and to interact with others on WeChat, a highly popular software, innovated by Tencent Company in 2011, which can be used to transmit instant messages, videos and pictures. Its functions and characteristics not only make it possible for teachers and students to use in teaching and learning, but also have the advantage of applying to language teaching and learning. It is worthwhile to analyze how to carry out collaborative learning of college English writing based on WeChat and to explore the feasibility and effectiveness so as to improve the students' initiative and the teaching efficiency.

\section{Literature Review}

When these three key words "college English writing" are typed in CNKI, there are a lot of academic studies about it from a variety of perspectives. Some scholars study college English writing teaching from the perspective of collaborative learning (Liu, 2009; Jiang, 2012; Wu \& He, 2014; Wang, 2016; He, 2016); some focus on the collaborative learning in college English writing via the internet-aided instruction (Yang, 2007; Liu \& Yang, 2008; Meng, 2011; Li \& You, 2014); and some study it based on blog, forum and E-mail (Zhao, 2009). The research mentioned here demonstrates: whether the theory of the collaborative learning singly or the collaborative learning via the internet tool has had a great effect on college English writing. To some extent, the above modes can help the students overcome the writing anxiety, improve the writing strategies and strengthen students' confidence of English writing. However, they also have some limitations and weaknesses: On one hand, these teaching modes are not always helpful to enhance students' writing motivation and interest; on the other hand, these means have some difficulties in balancing resources that a variety of students can enjoy, interacting instantly with each other and operating the process of teaching and so on.

No matter how many problems and difficulties there are in English writing teaching, there are scholars who have taken action to seek for solutions. The rise of WeChat, a newly developing instant communicative tool, provides a possible way to the above problems. WeChat can not only integrate all the features of the previous modes, but make up for their deficiencies. WeChat's own features and functions enable it to be applied to college English teaching. Till now, there are quite few researches on college English writing based on WeChat. This mode of college English writing based on WeChat, breaking the limitations of time and space of the traditional English writing, enables the students to learn English in scattered time, provide full freedom for the students to interact and discuss with other students and teachers, strengthen students' writing enthusiasm, enrich learning resources, teaching materials and writing forms, develop students' ability of self-reflection and improve students' ability of autonomous study (Jiang, 2016; Zhang, 2017; Shen, 2018; Tong, 2018). However, all of the research related to WeChat-based college English writing has overlooked to utilize collaborative learning which can play a greater role to develop students' team spirit, to stimulate students' motivation, to enhance students' self-confidence and finally to improve students' subjective initiative. Consequently, the author will integrate the advantages of WeChat with the theory of collaborative learning together and then exert their positive effects on college English writing to examine students' classroom learning and to further students' after-class learning.

\section{Theoretical Basis}

\subsection{The Theory of Constructivism}

Constructivism, firstly proposed by the prominent Swiss child psychologist J. Piaget, is a theory describing how learning happens and explaining how knowledge is constructed when information comes into contact with existing knowledge that had been acquired before. Furthermore, constructivism is a theory that emphasizes the subjective initiative and the importance of the learner being actively involved in the learning process, unlike previous educational viewpoints where the responsibility rested with the instructor to teach and where the learner played a passive and receptive role. Constructivism, which is strongly influenced by Vygotsky's work (1978), suggests that knowledge is first constructed in the interaction to a social context and is then appropriated by individuals. Vygotsky views that the process of sharing individual perspectives - called collaborative elaboration - results in learners constructing understanding together that wouldn't be possible alone. According to constructivism, learning, firstly, is an active process where learners should learn to discover principles, concepts and facts for themselves; secondly, instead of telling and giving a lecture, the teacher, who functions as a facilitator, a mentor, a consultant and a coach, is to aid the students when it comes to their own understanding; thirdly, knowledge is not instructed but constructed while the students interact, discuss, collaborate and help with each other/one another in a social culture throughout the process of learning. 


\subsection{The Theory of Collaborative Learning}

Collaborative learning is a strategy of learning that groups of learners in various performance levels work together and attempt to solve a problem, complete a task, or create a product. Collaborative learning is based on the idea that learning is a naturally social act in which the participants talk among themselves actively. The learners are to learn knowledge through the talk. In the process of collaborative learning, the learners are given an opportunity to engage in discussion and are responsible for one another's learning as well as their own. Collaborative learning requires that the learners have positive interdependence, individual accountability, interpersonal skills, promotive interaction, and processing. There is a persuasive evidence that collaborative groups/teams retain more information from thoughtful discussions than learners who work quietly as individual sand have a more positive attitude towards learning. According to collaborative learning, the role of an instructor is to help form groups before learning, to facilitate discussion and suggest alternatives while learning, and to comment after learning instead of imposing solutions on the team. With or without a form of technology, collaborative learning encourages the active exchange of ideas within small groups, which not only increases interest among the participants but also promotes problem solving and critical thinking.

\subsection{The Theory of Mobile Learning}

Mobile learning is a means of learning, education on new mobile technology, such as smart phones, laptops or tablets and other connected devices, which is playing a large role in how people, especially young people, receive information today. Mobile learning focuses on the mobility of the learner, interacting with portable technologies. Mobile learning is convenient in that it is accessible from virtually anytime and anywhere. Sharing is almost instantaneous among everyone using the same content, which leads to the reception of instant feedback and tips. Mobile learning, representing a way to address a number of educational problems with mobile devices used in conjunction with near universal $3 \mathrm{G} / 4 \mathrm{G} / 5 \mathrm{G}$ wireless connectivity, brings diverse digital content to students on one hand, and it is essential to improve learning for students on the other hand. As noted by Irwin Jacobs (2013), the founding chairman of Qualcomm, Inc., "always on, always connected mobile devices in the hands of students has the potential to dramatically improve educational outcomes." Additionally, it can be used to enhance student-centered learning, group collaboration among students through communication applications, interactive displays, and video features, and so on.

\section{Research Design}

There are undergraduates of two classes from Human Geography \& Planning with a total of 88 students (with 44 students in each class who were enrolled into Leshan Normal University in 2018) as the research object of thesis: Two classes should not only establish their class WeChat Group, but also the study WeChat Groups with 5-6 students in each group. All of students should change the nickname in the WeChat Group to the real name with the student number.

\subsection{Pre-test}

In order to know the students' current situation of English, a pre-test questionnaire was launched in these two class. The questionnaire before the test is as follows.

Table 1. The main aspects in the pre-test questionnaire

\begin{tabular}{ll}
\hline Questions & Answers (Percentage) \\
\hline 1. What do you think of your present level of English writing? & A. Above CET 4 (8\%) \\
& B. About CET 4 (30.7\%) \\
2. Are you confident of your English writing? & C. Below CET 4 (61.4\%) \\
& A. Very confident (3.4\%) \\
3. How often do you practice your English writing? & B. Confident (38.6\%) \\
& C. Not confident (58\%) \\
& A. About every week (11.4\%) \\
& B. About every two weeks \\
& C. Mo\%) \\
\hline
\end{tabular}


4. Do you usually collaborate and discuss with your classmates while writing?

5. Have you practiced English writing on WeChat Platform?

6. What do you think of your initiative of practicing English writing?
A. Always (2.3\%)
B. Seldom $(75 \%)$
C. Never $(22.7 \%)$
$\begin{array}{ll}\text { A. } & \text { Always }(1.1 \%) \\ \text { B. } & \text { Seldom }(56.8 \%) \\ \text { C. } & \text { Never }(42.1 \%)\end{array}$
A. Strong $(10.2 \%)$
B. Just-so-so $(60.2 \%)$
C. Weak $(29.6 \%)$

According to the pre-test questionnaire, most of the students are not satisfied with their English writing at all maily because of lacking confidence, collaboration, interaction, initiative of English writing.

\subsection{Post-test}

It took at least a semester to carry out WeChat English writing based on collaborative learning theory in these two class with these 88 students as the research object so as to demonstrate whether it is beneficial to improving their skills, confidence, initiative, etc of English writing. Afterwards, the students in these two class were asked to finish a questionnaire as follows.

Table 2. The main aspects in the post-test questionnaire

\begin{tabular}{|c|c|}
\hline Questions & Answers (Percentage) \\
\hline \multirow[t]{3}{*}{ 1. What do you think of your present level of English writing? } & A. $\quad$ Above CET $4(29.7 \%)$ \\
\hline & About CET 4 (56.9\%) \\
\hline & Below CET $4(13.4 \%)$ \\
\hline \multirow[t]{3}{*}{ 2. Are you confident of your English writing? } & Very confident $(19.6 \%)$ \\
\hline & B. Confident $(62.4 \%)$ \\
\hline & Not confident $(18 \%)$ \\
\hline \multirow[t]{3}{*}{ 3. What's your attitude toward group writing on WeChat Platform? } & Positive $(64.4 \%)$ \\
\hline & B. Neutral $(33.5 \%)$ \\
\hline & C. Negative $(2.1 \%)$ \\
\hline \multirow{3}{*}{$\begin{array}{l}\text { 4. What do you think of inner-group and inter-group review and } \\
\text { evaluation for your writing on WeChat Platform? }\end{array}$} & A. Very helpful $(49.6 \%)$ \\
\hline & B. Helpful (47\%) \\
\hline & C. Not helpful 3.4\%) \\
\hline \multirow{3}{*}{$\begin{array}{l}\text { 5. Are you willing to stick to this mode of practicing English } \\
\text { writing on WeChat Platform? }\end{array}$} & A. $\quad$ Yes $(67.6 \%)$ \\
\hline & B. Neutral (30.1\%) \\
\hline & C. $\quad$ No $(2.2 \%)$ \\
\hline \multirow{3}{*}{$\begin{array}{l}\text { 6. Whether is your initiative of practicing English writing } \\
\text { enhanced? }\end{array}$} & A. Very much $(57.8 \%)$ \\
\hline & B. Just-so-so (30.1\%) \\
\hline & Not at all $(12.1 \%)$ \\
\hline
\end{tabular}

From the pre-test questionnaire to the pos-test questionnaire, it was demonstrated that collaborative English writing on WeChat Platform, as a new mode of college English writing, definitely contributes to improving the students' writing skills, promoting their writing efficiency, increasing the frequency of interaction and communication, enhancing their initiative and encouraging their critical thinking. 


\subsection{Advantages}

As a complementary way of classroom writing teaching, collaborative English writing on WeChat Platform is mainly conducted after class for students' learning and practicing.

\subsubsection{Highlighting Students' Role in Learning}

The teacher mainly plays a role as instructor and guide in the pre-writing, the while-writing and the post-writing to create an atmosphere of knowledge construction, where students in groups engage in discussion, interaction, communication, consultation to construct knowledge and process their group writing.

\subsubsection{Improving Efficiency of Writing Practice}

This mode of English writing, mainly relying on mobile phones, can be virtually carried out without time and place restrictions. Students themselves can flexibly arrange their time for the group writing, commenting and revising anywhere at any time.

\subsubsection{Increasing Frequency of Interaction}

The student-student and student-teacher interaction can take place in the pre-writing, the while-writing and the post-writing. Obviously, in order to accomplish the task, students need to discuss, share, consult and collaborate with other students and teachers while the teacher needs to manage, guide and instruct the students in the whole process of writing.

\subsubsection{Enhancing Initiative of Students}

WeChat, especially group chat, supplies a more convenient platform for students and teachers to communicate with each other/one another freely and equally, which creates a pleasantly relaxing atmosphere for English teaching and learning instead of a tense atmosphere. Additionally, various writing resources such as instant messages, videos and pictures transmitted through WeChat tend to attract students' interests, stimulate their enthusiasm and enhance students' initiative of writing.

\subsubsection{Encouraging Critical Thinking}

This mode provides students with more opportunities to think about, to find out, to analyze and solve problems. Moreover, it helps create an environment for students and enables them to ask questions, to guess, to explore, to judge and to express their own ideas while they discuss, revise, comment and evaluate their own essays and the essays from other groups.

\subsection{Disadvantages}

According to the questionnaire before and after, most students admitted that they got a lot of benefits from collaborative English writing on WeChat Platform. However, there are still a few protruding problems which are relying on further and deeper studies in the future.

\subsubsection{Not Easy to Be Organized by the Group Leader}

WeChat-based English writing collaboratively relies on mobile phones, as mobile learning, which seems somewhat convenient and can be accessible from anytime and anyplace. However, it, firstly, is not easy to arrange for all students to stay online at the same time after class in order to accomplish the writing task. Secondly, it is not easy for students to concentrate themselves on collaborative writing because of time fragmentation. Thirdly, it is not easy to keep students' enthusiasm on collaborative writing because there are other factors at all times attracting students' attention which brings out the delay and procrastination of group writing on WeChat.

\subsubsection{Not Easy to Be Monitored by the Teacher}

Teachers should make full use of a variety of specific monitoring means consciously in order to achieve the best teaching and learning results. (Huang, 2014) However, as WeChat-based English writing collaboratively is usually carried out after class when students usually have many other extra-curricular activities to take part in, they have right and freedom to decide when to accomplish their assignments according to their own schedule as long as they think that they can accomplish the task of group writing before the deadline. Next, the inconsistency in their schedule makes it impossible for the teacher to monitor the progress of all groups in time.

\section{Implementation Procedures of WeChat-Based Collaborative Learning in College English Writing}

WeChat can contribute greatly to communication and interaction between students and teachers. And more generally, WeChat groups contribute to the propensity of students to promote, facilitate and enhance student-student interactions and collaborations, enabling students to generate ideas, giving students more 
chances to share data, files and messages. They can also be connected to a shared data network, further enhancing possibilities for communication, interactions and collaboration, so teachers must assist students to create an environment in which to participate in the learning process, and to work with that knowledge in an appropriate way.

\subsection{Establishing WeChat Group}

\subsubsection{Establishing a Class WeChat Group}

At the beginning of putting WeChat-based collaborative learning in English writing into practice, make sure all students download WeChat App to register their own WeChat account. Next, sweep two-dimensional code or search each other's name to be friends on WeChat. Thirdly, establish the class WeChat group by the teacher or the monitor and check whether all of the students and the teacher are in. Through WeChat, the teacher can not only publish the syllabus, teaching and learning objectives and other related information of English writing, which can be known to students in the whole class, but also can publish writing topics, writing requirements, questions and some other writing materials. What's more, the communication through WeChat can be easily done between the teacher and the students and among students, which is convenient for the teacher to know the students' tastes and interests and for the students to discuss the teaching content with the teacher and with other students.

\subsubsection{Establishing Several Study WeChat Groups in a Class}

Establishing study WeChat groups, with 5 to 6 students in each group as a team, is another preparation for collaborative learning of English writing. While study groups are established, most importantly, students' personalities, interests, genders and the level of English should be taken into consideration in order to make all of the study groups relatively well-matched in strength. Additionally, each study group has a team leader and a recorder, who are in charge of the team work. The students in each group can take their turns leading their team as writing tasks change. The group leader and the recorder will have a chance to get a reward in score if their team finish a high-quality writing; and accordingly, they will be punished by being given a lower score if they are not responsible for their group writing. Obviously, it is an effective way to practice students' ability of management and organization and to develop students' sense of responsibility and team spirit.

As WeChat groups at different levels are established, the students and the teacher can begin to talk with each other/ one another about the writing topic. In the class WeChat group, the students can discuss with the teacher and the teacher can instantly know whether the writing topic meet the students' tastes and interests. In study WeChat group the teacher can know whether the students' discussion in their groups are going on effectively in order to push them forward if necessary.

\subsection{Discussing and Group Drafting}

According to Bruner in 1966, constructivist learning is an active process in which learners construct new ideas or concepts based on their current and past knowledge. Within a constructivist learning framework, students should be encouraged to discover principles for themselves. In order to transform learners from passive recipients of information to active constructors of knowledge, teachers must create an environment for learners in which learners can participate in the learning process with ease, and come up with an appropriate and effective way to work with that knowledge. So, when the writing task is published by the teacher, it will be given one-week duration for students to discuss, interact, consult and collaborate so as to work out a writing product. And usually, the students are suggested to follow the steps here:

For the first two days, students in the same study group as a team will discuss and try to generate as many as related ideas on the topic through immediate WeChat. Students in the same team, whether they choose to communicate by using text message or by using voice message, can express what they know in the chat window easily and clearly on one hand, and other students can get to know what they may not know, which can promote students to discuss with each other/one another as possible as they can before working on their essay writing on the other hand. While discussing, students can share their ideas about the writing task to clarify the topic, to structure the essay, to write out the outline, to list the keys words, phrases, expressions, sentence structures and grammatical points, to discuss the introduction, the body and the conclusion of the essay and to set up a plan of their group writing.

For the second two days, students can further discuss their writing plan because, as a matter of fact, discussion may never stop from the beginning of writing to the end of that among students in the same team and between student(s) and teacher. Based on the preparation and the discussion, the group/team leader can decide to write the essay by using the keys words, phrases, expressions, sentence structures and grammatical points and by 
following the outline that has been listed. Students can type their writing draft directly in the chat window and also write the draft on a piece of paper (they can take a picture and then upload it to the WeChat group).

For the third two days, the team leader posts the draft into the study WeChat group and all of the team members are asked to read it extensively and intensively. Each student should revise the writing as specifically and persuasively as possible in terms of content, language, vocabulary, structure and organization etc. Then, students will discuss what they come up with individually in order to judge what aspects their draft really needs to be modified. Finally, the team leader will synthesize the ideas and improve their writing.

For the last day, the group leader, firstly, will share the second draft with the team members in the study WeChat group for further improvement if possible and necessary. At the same time, all of the study groups are asked to share their writing in the WeChat Circle of Friends.

In the process of group writing before being submitted in the WeChat Circle of Friends, the students in the same group discuss, interact, consult, and collaborate in order to accomplish the writing task. The students are put in the center of learning to construct knowledge themselves while the teacher plays the role in writing as a facilitator, a mentor, a consultant and a coach to assist the students further their understanding. The ability of students' writing, according to a research, is constructed and developed in the process of discussion, consultation and cooperation with peers. Positive interdependence and communication cooperation make the students expand the scheme, share resources, improve thinking, solve the problems of writing, construct knowledge, accomplish the writing task cooperatively, develop the ability of writing. (Wu \& He, 2014)

\subsection{Revision and Evaluation}

The writing of each group will be revised several times according to the suggestions from the group members, other groups and the teacher. At the same time, the writing of each group will be evaluated by their own group as a team, other groups and the teacher. Whether it is inner-group revision and evaluation, inter-group or the teacher's revision and evaluation, the students and the teacher must follow the guideline:

\section{The Guideline for Revision and Evaluation}

\begin{tabular}{ll}
\hline Organization & 1. Include introduction, body and conclusion: YES/NO? \\
2. Have a clear main idea/message: Yes/NO \\
3. Have a topic sentence in each paragraph: Yes/NO \\
1. Have supporting details on the topic: Yes/NO \\
2. Have clear meaning of each sentence: Yes/NO \\
3. Transit each two sentences naturally: Yes/NO \\
1. Have appropriate word choice: Yes/NO \\
2. Use right grammar: Yes/NO \\
3. Spell the words correctly: Yes/NO
\end{tabular}

\subsubsection{Inner-group Revision and Evaluation}

The inner-group revision and evaluation will be done by the group/team members in the study WeChat group before the draft is uploaded onto the WeChat Circle of Friends. At first, all of the group members are asked to read it extensively and intensively and to revise the writing as specifically and persuasively as possible in terms of content, language, vocabulary, structure and organization etc. Then, students will discuss their own ideas of revision through WeChat exchange in order to judge in what aspects their writing really needs to be modified. Thirdly, the team leader will synthesize the ideas and improve their writing. Finally, after their writing is further improved, the group will self-evaluate their group writing objectively based on their negotiation.

\subsubsection{Inter-group Revision and Evaluation}

The inter-group revision will be done after the writing of each group being uploaded onto the WeChat Circle of Friends. All of the students in the class, on one hand, are asked to read the writing from other groups carefully and specifically to check whether the writing has the introduction, body and conclusion, whether the main idea/message is clear, whether the paragraphs have logical sentences, whether the transition between each two sentences is natural, and whether there are grammar and spell mistakes; on the other hand, they are asked to 
revise and objectively comment the writing of other groups in order to help them to perfect their group writing. At the same time, each group need objectively and fairly score the writing of other groups one by one. In fact, students learn from each other in the process of the mutual evaluation so that they can find the problems of others and put forward suggestions on the one hand. On the other hand, they will also enhance their own awareness of similar problems and improve their ability of language use and critical thinking (Wang, 2016).

\subsubsection{Teacher's Revision and Evaluation}

Teacher's revision will also be done when the writing of each group is published in the WeChat Circle of Friends. Usually, the teacher's revision and evaluation will be given after that of the students in order not to affect their judgements. Without any exception, the teacher should necessarily take the aspects of the guide of revision and evaluation into consideration. However, most of all, the teacher's revision and evaluation should not only focus on the whole structure of the writing, the logicality of the paragraphs, but also affirm the strong points of each writing which can help students develop the sense of self-confidence in English writing.

Students' self-evaluation, peer evaluation and teacher evaluation can be combined to make a more comprehensive, objective and scientific evaluation of students' learning activities from multiple aspects and perspectives. (Liu \& Yang, 2008) Actually, the ultimate goal of the evaluation and revise from inner-group, inter-group and the teacher is "not seeking success for everyone, but seeking progress for everyone" (Wang, 2002). Therefore, when inner-group, inter-group and the teacher's revision and evaluation is done, each group need give a final modification and perfection of their group writing according to the feedback before the teacher keeps their writing on file. The scores will be given based on the inner-group, the inter-group and the teacher and will be prorated into the final score. The percentage of the score from each part depends on the requirements the teacher has announced to the class before. The inner-group, inter-group and teacher's revision and evaluation maximizes the interaction between the students and the teacher, and among students themselves for one thing, and for another, stimulates students to play their own initiative in English writing.

\section{Conclusion}

In conclusion, the WeChat-based English writing mode supported by mobile phones, keeps pace with the latest information technology, which changes the mode of traditional college English writing greatly. Besides, various teaching theories such as constructivism, collaborative learning and mobile learning can really be adopted in the process of WeChat-based English writing, which makes the teacher an organizer, coordinator and supervisor and students the hosts of learning. The WeChat-assisted college English writing based on the theory of collaborative learning produces an effective solution of the problems of traditional teaching such as time-consuming, poor efficiency, limit of time and place, unitary form, boring content etc. This teaching model of English writing creates learning to be an active process where students construct knowledge themselves, which can promote the interaction among students and between students and teachers, develop the team spirit of students, enhance students' initiative and encourage students to think critically. With the development of new technologies, the new functions of WeChat will come out, in order to further improve the efficiency of college English writing teaching and learning, college English teachers should keep up with the development of new technologies, constantly improve the awareness, knowledge and ability of using information technology and actively integrate and rationally utilize the various advanced theories of teaching and learning in the specific teaching design and implementation process.

\section{References}

China Internet Network Information Center (CN-NIC). (2019). 43rd China Internet Development Report. Retrieved from https://www.yicai.com/news/100127009.html

He, L. (2016). The Application of Task-Based Cooperative Learning Approach in College English Writing Teaching. Jinan: Shandong Normal University.

Higher Education Department of the Ministry of Education of China. (2017). College English Teaching Guide. Retrieved from https://www.sohu.com/a/125489097_488760

Huang, L. (2014). Experimental Study on the Correlation Between Teacher Monitoring and Students' Participation in Oral English Classes under Cooperative Learning Environment. Knowledge Economy, 9, 172.

Jacobs, I. (2013). Modernizing Education and Preparing Tomorrow's Workforce Through Mobile Technology. Summit, 5, 2.

Jiang, P. (2016). The Application of WeChat in College English Writing — From the Perspective of Writing 
Ecological Theory. Journal of Hubei University of Economics (Social Sciences), 3, 213-214.

Jiang, Q. J. (2012). A Study of the Application of Cooperative Learning Theory in College English Writing Teaching. Wuhan: Central China Normal University.

Li, L. H., \& You, H. N. (2014) The Application of Cooperative Learning in College English Writing Teaching under Network Environment. Science and Technology Vision, 35, 226-227

Liu, X. L., \& Yang, G. Y. (2008). A Study on Web-Based Peer Revision in College English Writing. Foreign Languages in China, 2, 54-58.

Liu, Y. F. (2009). Research on College English Writing Teaching Based on Cooperative Teaching Theory. Jinan: Shandong Normal University.

Meng, X. L. (2011). The Application of Task-Assisted Cooperative Learning Model to College English Writing Teaching. Xi'an: Northwest Agriculture and Forest University.

Tong, S. (2018). Research on "WeChat +" Assisted English Writing Teaching Model from the Perspective of Constructivism. Overseas English, 12, 74-75.

Wang, K. (2016). The Application of Group Cooperation Model in College English Writing Learning and Teaching. Innovation and Exploration: Collected Works of Foreign Language Teaching and Research, 3, 164.

Wang, T. (2002). On the Basic Idea of Cooperative Learning. Educational Research, 2, 72. https://doi.org/10.3102/00346543072003481

Wu, R. H., \& He, G. D. (2014). Research on the Application Effect of Cooperative Learning in College English Writing Teaching. Foreign Language Teaching, 3, 46.

Yang, G.Y. (2007). A Study on Web-Based Collaborative Learning in College English Writing. Changsha: Hunan University.

Zhang, K. X. (2017). Research on College English Writing Teaching Based-on WeChat. Harbin: Harbin University of Science and Technology.

Zhao, Y. X. (2009). Research on Blog-Based Peer Review in EFL Writing. Shanghai: Shanghai International Studies University.

\section{Copyrights}

Copyright for this article is retained by the author(s), with first publication rights granted to the journal.

This is an open-access article distributed under the terms and conditions of the Creative Commons Attribution license (http://creativecommons.org/licenses/by/4.0/). 